
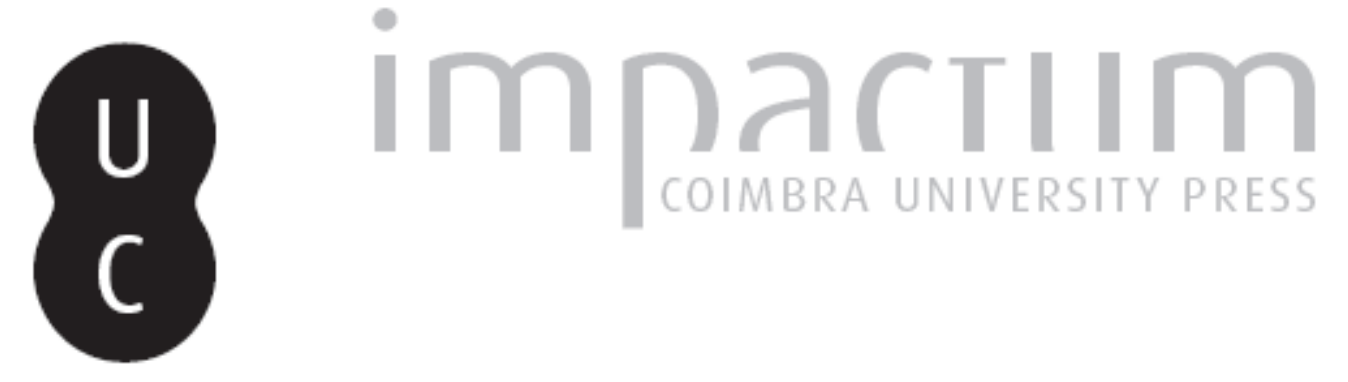

\title{
Educação para o risco e desenvolvimento sustentável na formação de futuros cidadãos
}

\author{
Autor(es): $\quad$ Vigário, Carla; Talaia, Mário \\ Publicado por: Imprensa da Universidade de Coimbra \\ URL \\ persistente: \\ URI:http://hdl.handle.net/10316.2/44189 \\ DOI: \\ DOI:https://doi.org/10.14195/1647-7723_25-2_3
}

Accessed : $\quad$ 26-Apr-2023 08:46:40

A navegação consulta e descarregamento dos títulos inseridos nas Bibliotecas Digitais UC Digitalis, UC Pombalina e UC Impactum, pressupõem a aceitação plena e sem reservas dos Termos e Condições de Uso destas Bibliotecas Digitais, disponíveis em https://digitalis.uc.pt/pt-pt/termos.

Conforme exposto nos referidos Termos e Condições de Uso, o descarregamento de títulos de acesso restrito requer uma licença válida de autorização devendo o utilizador aceder ao(s) documento(s) a partir de um endereço de IP da instituição detentora da supramencionada licença.

Ao utilizador é apenas permitido o descarregamento para uso pessoal, pelo que o emprego do(s) título(s) descarregado(s) para outro fim, designadamente comercial, carece de autorização do respetivo autor ou editor da obra.

Na medida em que todas as obras da UC Digitalis se encontram protegidas pelo Código do Direito de Autor e Direitos Conexos e demais legislação aplicável, toda a cópia, parcial ou total, deste documento, nos casos em que é legalmente admitida, deverá conter ou fazer-se acompanhar por este aviso.

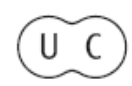




\section{EDUCAÇÃO PARA O RISCO E DESENVOLVIMENTO SUSTENTÁVEL NA FORMAÇÃO DE FUTUROS CIDADÃOS*}

EDUCATION FOR RISK AND SUSTAINABLE DEVELOPMENT IN THE TRAINING OF FUTURE CITIZENS

Carla Vigário

Departamento da Educacão e Psicologia da Universidade de Aveiro (Portugal) ORCID 0000-0003-0291-209X carlasofia213@gmail.com

Mário Talaia

CIDTFF - Centro de Investigação Didática e Tecnologia na Formação de Formadores Departamendo de Física da Univ. Aveiro (Portugal) ORCID 0000-0003-4311-6209 mart@ua.pt

\section{RESUMO}

De acordo com o Conselho Nacional de Educação vive-se numa sociedade que é sistematicamente confrontada com notícias sobre a presença do risco, desde riscos naturais aos que resultam diretamente da ação humana, sendo certo que se interligam fortemente. Por isso, desenvolver conhecimentos relacionados com a vida, nomeadamente, sobre as plantas comestíveis, os fenómenos envolvidos no seu desenvolvimento ou o seu tratamento e cultivo, com recursos de baixo custo, é considerado uma forma de contribuir para a formação de cidadãos. Sendo assim, este trabalho mostra a importância de como uma horta, enquanto extensão de sala de aula, pode construir conhecimento científico e desenvolver competências e cidadania em alunos, futuros cidadãos, que mais tarde poderão ter o privilégio de tomarem decisões de planeamento ambiental e florestal. Os resultados obtidos mostraram que é possível verificar a importância das plantas como fundamentais para toda a vida na terra. Foram interpretadas as diferenças do desenvolvimento das plantas em céu aberto e em estufa e valorizou-se a rega natural durante a noite através da formação do orvalho.

Palavras-chave: Sustentabilidade, educação para o risco, estufa, desenvolvimento de plantas, orvalho, cidadania.

\section{ABSTRACT}

According to the National Education Board, we live in a society that is systematically confronted with news about the presence of risk, from natural risks to those that result directly from human action, and they are sure to be closely interconnected. Therefore, developing life-related knowledge, particularly about edible plants, including the phenomena involved in their development or treatment and cultivation using low-cost resources is seen as a way of helping with the training of citizens. Thus, this work shows the importance of how a vegetable garden, as an extension of the classroom, can build scientific knowledge and develop skills and citizenship in students, future citizens, who may later have the privilege of making environmental and forest planning decisions. The results showed that it is possible to confirm the importance of plants as fundamental for all life on earth. Differences in the development of open air and greenhouse plants were interpreted and natural irrigation was evaluated at night through the formation of dew.

Keywords: Sustainability, education for risk, greenhouse, plant development, dew, citizenship.

\footnotetext{
* O texto deste artigo corresponde a uma comunicação apresentada no IV Congresso Internacional de Riscos, tendo sido submetido em 26-06-2017, sujeito a revisão por pares a 22-09-2017 e aceite para publicação em 02-01-2018. Este artigo é parte integrante da Revista Territorium, $n .{ }^{\circ} 25$ (II), 2018, ${ }^{\circ}$ RIscos, ISSN: 0872-8941.
} 


\section{Introdução}

A atualidade global planetária está marcada pelo rápido crescimento científico e tecnológico, sem paralelo na história da humanidade. Áreas como sociedade, cultura, ambiente e economia sofreram várias mudanças, com implicações na adoção de estratégias de intervenção (UNESCO, 2005; UNESCO, 2014). Com o desenvolvimento da economia global, em simultâneo com melhores acessos à informação e à cultura, foram proporcionadas melhores condições de vida às sociedades, mas, em contrapartida, emergiram outros novos problemas. Deste modo, o aumento da população mundial, como nunca antes tinha acontecido, e o aumento dos consumos sugerem que se está a viver uma época que abre caminho para uma preocupação ou problemática global, a qual está a pôr em risco a sustentabilidade do planeta. Estas circunstâncias têm gerado grandes confrontos políticos e sociais, dando origem a questões sobre a disponibilidade de recursos para as gerações futuras. De entre eles, a água continua a ser a base de grandes discussões e é estudada através de um comité científico internacional, o IPCC (Intergovernamental Panel on Climate Change). Como é sabido, há questões, problemas, que afetam a humanidade, nomeadamente as alterações climáticas e o aquecimento global (IPCC, 2014a; IPCC, 2014b).

Segundo as Nações Unidas (UNFPA, 2007) prevê-se um crescimento exponencial da população global nas próximas décadas, sobretudo nos países em desenvolvimento, com uma tendência de maior crescimento entre a população urbana face à população rural. Este é um dos grandes problemas de Portugal, uma vez que as zonas do interior estão a ser abandonadas, por falta de incentivos, e muitos dos que ainda acreditam no valor da vida nessas regiões, despendem de muito mais dinheiro do que aqueles que residem nas zonas urbanas para terem condições de vida semelhantes (deslocações longas e muitas vezes demoradas para fazer face a assistência médica, bancos, fazer compras em mercados, estudar, trabalhar, repartições públicas, etc.).

Investir e viver no interior merece coragem e o conhecimento exato de que parte do salário ficará aplicado em transportes, como se essa população pagasse mais um imposto indireto, como penalização de viver no interior. Por outro lado, a taxa de natalidade não corresponde à necessária sustentabilidade do país e é a zona rural a que mais sofre pela ausência de novos habitantes e pelo contínuo despovoamento.

Se não houver políticas para a fixação de habitantes no interior do país, conservar a vida nesse interior tornarse-á um foco de despesas imprevisível para as entidades de proteção pública. As vias de comunicação, muitas com taxas de portagem, oneram a vida dos habitantes rurais e esta situação pode fazer a diferença para que novos casais se fixem nas zonas urbanas. Com efeito, a diferença na poupança financeira pode ser, para esses casais, gasta em entretenimento. Como é sabido, em termos gerais, várias hortas de apoio, em termos de alimentação, existentes nas zonas rurais, muitas vezes foram substituídas por plantação de eucalipto e/ou pinheiro.

Por outro lado, a carga de combustível é um contributo da vegetação para aumentar a facilidade de ignição e dificultar a extinção de um incêndio, contribuindo por isso para aumentar o risco de incêndio e que, ao manifestar-se, poderá transformar-se em catástrofe para uma dada região. Num eucaliptal, o perigo de progressão é proporcional à densidade da plantação. 0 mesmo poderá ser afirmado face a um pinhal de pinheiro-bravo. Em regra, o pinhal de pinheiro-manso regista, no caso de presença de incêndio, um menor potencial de destruição. Neste contexto, o sistema político deverá considerar as vantagens de apoiar a população, de modo a fixar habitantes em regiões rurais, nomeadamente protegendo as áreas de habitação através de cortinas de árvores de crescimento lento, que possam servir de corta-fogo.

Com efeito, no documento colocado em consulta pública, cujo título é "Referencial de Educação para o Desenvolvimento - Educação Pré-Escolar, Ensino Básico e Ensino Secundário" (Torres et al., 2016) pode ler-se que, a par da variada rede de conceitos diretamente associados ao desenvolvimento, denota-se, ao nível de diferentes instituições internacionais (United Nations, 2013; Comissão Europeia, 2013; OECD, 2015), uma preocupação crescente com a natureza multidimensional do bem-estar, assente na centralidade das pessoas nos processos de desenvolvimento, bem como nas suas aspirações e direitos. Além disso, também afirma a necessidade de um quadro abrangente, comum sobre os desafios globais do desenvolvimento, que, de forma indissociável com os direitos humanos, contemple, entre outras, as questões ligadas à governação e à paz e segurança.

Nesta perspetiva, considera-se que desenvolver conhecimentos relacionados com a vida, nomeadamente, das plantas comestíveis, dos fenómenos envolvidos no seu desenvolvimento e no seu tratamento e cultivo, com recursos de baixo custo, é uma forma de contribuir para a formação de cidadãos de modo a aumentar os seus conhecimentos neste âmbito e, assim, potenciar uma maior capacidade de sustentabilidade, que é um dos fatores fundamentais necessários à manutenção da paz no mundo.

Segundo a mesma fonte, deve-se reconhecer que a escola deve assumir um papel fundamental, em todos os níveis e ciclos de educação e ensino, proporcionando a aquisição de conhecimentos, o desenvolvimento de capacidades e a promoção de valores, atitudes e comportamentos que 
permitam às crianças e aos jovens a compreensão crítica e a participação informada perante desafios locais e globais que se colocam à construção de um mundo mais justo, inclusivo e solidário.

A necessidade de integrar os esforços de Educação para o Desenvolvimento no domínio da educação formal, tirando pleno partido de abordagens didáticas e pedagógicas adequadas para alcançar o público europeu, traduz uma preocupação expressa no Consenso Europeu sobre o Desenvolvimento, através do contributo da educação e da sensibilização para o desenvolvimento, em declaração conjunta, do Conselho e dos Representantes dos Governos e dos Estados-Membros reunidos no Conselho do Parlamento Europeu e da Comissão, sobre a política de desenvolvimento da União Europeia, aprovada em 2005 (European Multi-Stakeholder Steering Group on Development Education, 2007).

A atividade humana, por consequência da atual evolução, irá provocar alterações relacionadas com a utilização dos recursos naturais disponíveis, assim como a ocupação e a dominância de comunidades minoritárias para obtenção desses recursos. Factos como estes estão a conduzir à degradação ambiental e a desequilíbrios nos ecossistemas, espécies e culturas, acrescida da sobreexploração das comunidades mais desfavorecidas, pelas sociedades mais desenvolvidas, levando ao levantamento de questões preocupantes, como a sustentabilidade das gerações futuras, nomeadamente ao nível do acesso a alimentos e à qualidade do ambiente.

Nesta perspetiva, o ensino e a aprendizagem deverá dar a conhecer que o conhecimento científico está na sociedade e, daí, ter um papel social, nomeadamente na redução da pobreza e em práticas de desenvolvimento sustentável das gerações futuras (Martins, 2002).

O documento publicado pelo Ministério da Educação, em fevereiro de 2017, para consulta pública "Perfil dos Alunos para o século XXI" e que foi elaborado pelo Grupo de Trabalho criado nos termos do Despacho n. ${ }^{\circ}$ 9311/2017 de 21 de julho, cita no seu prefácio os sete pilares de E. Morin (1999), ou seja, os sete saberes para a Educação do Futuro e que são: compreender as cegueiras do conhecimento: o erro e a ilusão; os princípios do conhecimento pertinente; ensinar a condição humana; ensinar a identidade terrena; enfrentar as incertezas; ensinar a compreensão; e desenvolver a ética do género humano, de acordo com uma cidadania inclusiva.

Como, no prefácio deste livro, escreveu Guilherme d'Oliveira Martins "as humanidades hoje têm de ligar educação, cultura e ciência, saber e saber fazer" (C. S. Gomes, et al., 2017), fazer esta narrativa pode parecer um vazio, pois o seu alicerce passará por decisões políticas tendentes a que inúmeros habitantes se possam fixar em zonas rurais.
A educação poderá contribuir para alcançar esse desiderato. Por exemplo, na atualidade e em meio urbano, são muitas as escolas que possuem uma horta pedagógica que poderá ser explorada de diversas formas. Este é um recurso que pode ser valorizado, por parte dos alunos, desde a educação pré-escolar até ao ensino básico, em atividades promotoras de uma maior consciência e de um maior conhecimento acerca da origem dos produtos alimentares e das formas de obter produtos para alimentação a baixo custo (por exemplo, mostrar que reutilizando garrafões de água de $5 \mathrm{~L}$ podem ser criadas condições de estufa para as plantas cultivadas, podendo o educador encontrar potencial de exploração de diversos fatores naturais através deste uso simples e económico).

Por sua vez, em ambiente rural, as crianças acompanham a dinâmica de sustentabilidade com base na criação de hortas. Infelizmente, em muitas zonas rurais verifica-se a redução desta prática. As famílias mais jovens procuram alternativas de subsistência em círculos urbanos ou grandes metrópoles, penalizando a sobrevivência de aldeias e de freguesias do interior do país. A aprendizagem de vida facultada por familiares mais idosos é considerada de tábua rasa e outras alternativas de vida são assumidas como correspondentes a uma alteração do ecossistema, na procura de um bem-estar fictício de uma qualquer grande metrópole.

Neste trabalho, de acordo com os conteúdos programáticos para o $1 .^{\circ} \mathrm{CEB}$, a horta pedagógica surge, assim, como um meio para mostrar que a prática oferece a oportunidade para desenvolver nos alunos a capacidade de se construir conhecimento e respeito pela natureza (Driver et al., 2000). Foram consideradas diferentes plantas, como por exemplo a couve, a alface e o pimenteiro, cultivadas em diferentes ambientes (estufa e céu aberto) e, simultaneamente, procurou conhecer o aumento do conhecimento dos alunos sobre a importância das plantas para a vida no planeta, quer como base da cadeia alimentar, quer .como fornecedoras de oxigénio e consumidoras de dióxido de carbono.

\section{Teoria e Métodos}

O Programa de Estudo do Meio para o $1 .^{\circ} \mathrm{CEB}$, no que respeita ao bloco 3 - à descoberta do ambiente natural (Ministério da Educação, págs. 115-118, sem data), envolve "os conteúdos relacionados com os elementos básicos do meio físico (o ar, a água, as rochas, o solo), os seres vivos que nele vivem, o clima, o relevo e os astros". Este documento apela à estimulação da curiosidade infantil pelos fenómenos naturais e ao encorajamento dos alunos para o levantamento de questões e procura de respostas, através de atividades como "experiências e pesquisas simples". Além disso, o programa salienta a importância dos alunos realizarem "registos daquilo que 
observam", devendo ser o professor a incentivar atitudes nos alunos de "respeito pela vida e pela Natureza", e a "sensibilizá-los para os aspetos estéticos do ambiente".

As crianças são atentas ao que as rodeia e, por isso, sabem ouvir e colocar questões quando, por exemplo, no período mais "seco" do ano, os incêndios tornam o país insuportável para passar dias de lazer e tentam questionar as razões da existência de tanto estrago na natureza.

Neste contexto, foram realizadas atividades práticas de índole investigativa (metodologia do tipo investigaçãoação) em extensão de sala de aula, a céu aberto. Os materiais utilizados são simples, acessíveis e de baixo custo, numa relação dinâmica entre teoria e prática, conseguida através da resolução de questões. A amostra utilizada é considerada probabilística por conveniência, ou acidental (Cohen et al., 2010), constituída por alunos de uma turma do $2 .^{\circ}$ ano do $1 .^{\circ} \mathrm{CEB}$ na região centro do país.

Uma vez definidas as técnicas de recolha de dados mais adequadas, foi construído um questionário com questões abertas e os alunos foram informados da possibilidade de responderem por escrito ou através de representação gráfica (desenho ou imagem). De acordo com Vilelas (2009), as questões abertas têm a vantagem de registarem não só mais informação, mas também informação mais rica e pormenorizada, além de inesperada e, ainda, maior liberdade de resposta e menor influência do inquiridor.

O método qualitativo, relacionado com o desenvolvimento das plantas, foi inserido neste trabalho como forma de melhor compreender os factos inerentes ao processo envolvido neste desenvolvimento e as diferenças existentes entre diferentes condições ambientais das plantas (em estufa ou em céu aberto).

O método quantitativo teve por base a coleção de dados registados através das medições efetuadas, temperatura do ar e altura da planta, assim como das respostas dos alunos aos inquéritos por questionário. De um modo geral estes métodos (quantitativo e qualitativo) complementam-se.

O questionário composto por questões abertas foi aplicado antes (como objetivo conhecer as competências e conhecimentos prévios dos alunos sobre a temática) e depois da aplicação da estratégia de ensino ser implementada. Consideraram-se quatro possíveis respostas a cada questão: Respostas Cientificamente Corretas (RCC), nestas o aluno responde de forma correta e científica; Respostas Parcialmente Correta (RPC), nestas o aluno responde de forma incompleta, mas o que responde está cientificamente correto; Respostas Incorretas (RI), nestas o aluno ou responde totalmente de forma cientificamente incorreta ou mistura o que é cientificamente correto e incorreto; por último Não Responde (NR) o aluno não dá resposta.

O questionário foi introduzido com a informação "sabes que a vida no planeta terra depende do sol, da água e da atmosfera. As plantas necessitam destes fatores para crescerem. Sem plantas, não seria possível a existência de vida no planeta terra".

- 1 1. $^{\mathrm{a}}$ Questão:

a) Há plantas que podem ser facilmente cultivadas em pequenos espaços. Indica 5 plantas que podem ser cultivadas por ti ou pela tua família. Resposta esperada: Qualquer planta que se adapte ao clima da região é possível ser plantada. A resposta é livre, esperam-se respostas diversificadas, tais como, por exemplo, plantas ornamentais, plantas utilizadas na alimentação e plantas de diferentes alturas, desde as mantidas em vasos, até árvores de grande porte;

b) Das plantas que referiste, quais pensas que também podem ser cultivadas em vasos $e$ mantidas na varanda? Espera-se que os alunos respondam quais as plantas que consideram que podem ser mantidas em vasos, de acordo com os seus conhecimentos e conjeturas;

- $\quad$ 2. ${ }^{\text {a }}$ Questão: De que é que as plantas precisam para crescer? A resposta é considerada cientificamente correta sempre que os alunos responderem a 2 items. Os alunos deverão responder de acordo com os seus conhecimentos, incluindo na resposta fatores como, por exemplo, água, luz, solo fértil, atmosfera (os fatores envolvidos no processo de fotossíntese são considerados cientificamente corretos);

- $\quad$ 3. a Questão: Que cuidados é preciso ter para que uma planta cresça bem? Se os alunos responderem a 2 items, a resposta é considerada cientificamente correta, por exemplo: corte (podas), mondas, regas, colocar em lugar iluminado e, por vezes, protegido do sol direto;

- $\quad 4 .^{a}$ Questão: Que animais conheces e que podem ser amigos da horta? Pretende-se, com esta pergunta, que os alunos mencionem animais que identifiquem e que sejam favoráveis à horta. A resposta pode ser, por exemplo: minhoca, sapo, joaninha, aranha, libélula, abelha;

- 5. ${ }^{\text {a }}$ Questão: Dá 3 exemplos de alimentos que consumas e que sejam partes de plantas. $\mathrm{Na}$ resposta, os alunos devem mencionar, por exemplo: folha de alface, folha de couve, tomate;

- $\quad$ 6. ${ }^{\mathrm{a}}$ Questão:

a) Dos animais apresentados, identifica se alguns deles são prejudiciais para a horta e, nesse caso, indica quais deles o são, sublinhando os seus nomes. Pretende-se, com esta pergunta, que os alunos sublinhem a lagarta e o caracol; 
b) O que é que os animais que identificaste fazem de prejudicial? Espera-se que, na resposta, os alunos mencionem, por exemplo, que comem as folhas;

- $\quad$ 7. ${ }^{a}$ Questão: Na tua opinião, em qual das situações seguintes a planta está: (une os pontos de acordo com a tua opinião). 0 objetivo desta pergunta visa que os alunos tracem uma linha que una pontos, fazendo ligações corretas.

\section{Resultados e discussão}

\section{Extensão de sala de aula}

No local destinado à criação da horta, começou por se realizar a preparação do terreno. Depois, procedeuse à plantação de diferentes plantas e à colocação de garrafões de plástico, para fazerem o efeito de estufa. Finalmente, traçou-se o plano de rega, de recolha de informação (temperatura do ar, estado do tempo e altura das plantas) e de diversos tipos de observação visual, designadamente de: (I) animais presentes na horta e o seu papel (negativo ou positivo); (II) comparação entre as plantas cobertas pelos garrafões e as plantas descobertas em céu aberto (crescimento, aspeto, ataques de animais, ...); (III) interior dos garrafões, com gotículas de água presentes na parede interna de cada garrafão e troca de ideias sobre o fenómeno, nomeadamente a explicação de que o ar tem água que não se vê, chamada vapor de água, e que em contato com uma superfície com baixa temperatura, neste caso o plástico do garrafão, se pode transformar em gotículas que embaciam a parede interna do garrafão e que ajudam a regar as plantas pois a observação visual mostra que o solo está húmido (M. Talaia e C. Vigário, 2016). A utilização dos garrafões permite, também, a proteção do ataque de animais.

Os resultados do questionário, antes (pré-questionário) e depois (pós-questionário) da aplicação da estratégia de ensino, mostram resultados claramente distintos (fig. 1).

Assim, na alínea a) da 1. ${ }^{a}$ Questão, no pré-questionário, os resultados dos alunos mostraram que antes da abordagem da temática cerca de $21 \%$ não respondeu (NR), à volta de $8 \%$ registaram uma resposta incorreta (RI), aproximadamente $8 \%$ dos alunos identificaram as plantas (RCC) e cerca de $63 \%$ dos alunos identificaram plantas, mas em número inferior ao solicitado (RPC). Por sua vez, no pós-questionário, os resultados obtidos mostraram uma excelente melhoria, pois todos os alunos responderam e não se registaram respostas incorretas. Cerca de $87 \%$ dos alunos respondeu cientificamente correto (RCC), ou seja, identificaram 5 plantas; apenas cerca de $13 \%$ dos alunos responderam parcialmente correto porque identificaram um número inferior de plantas.

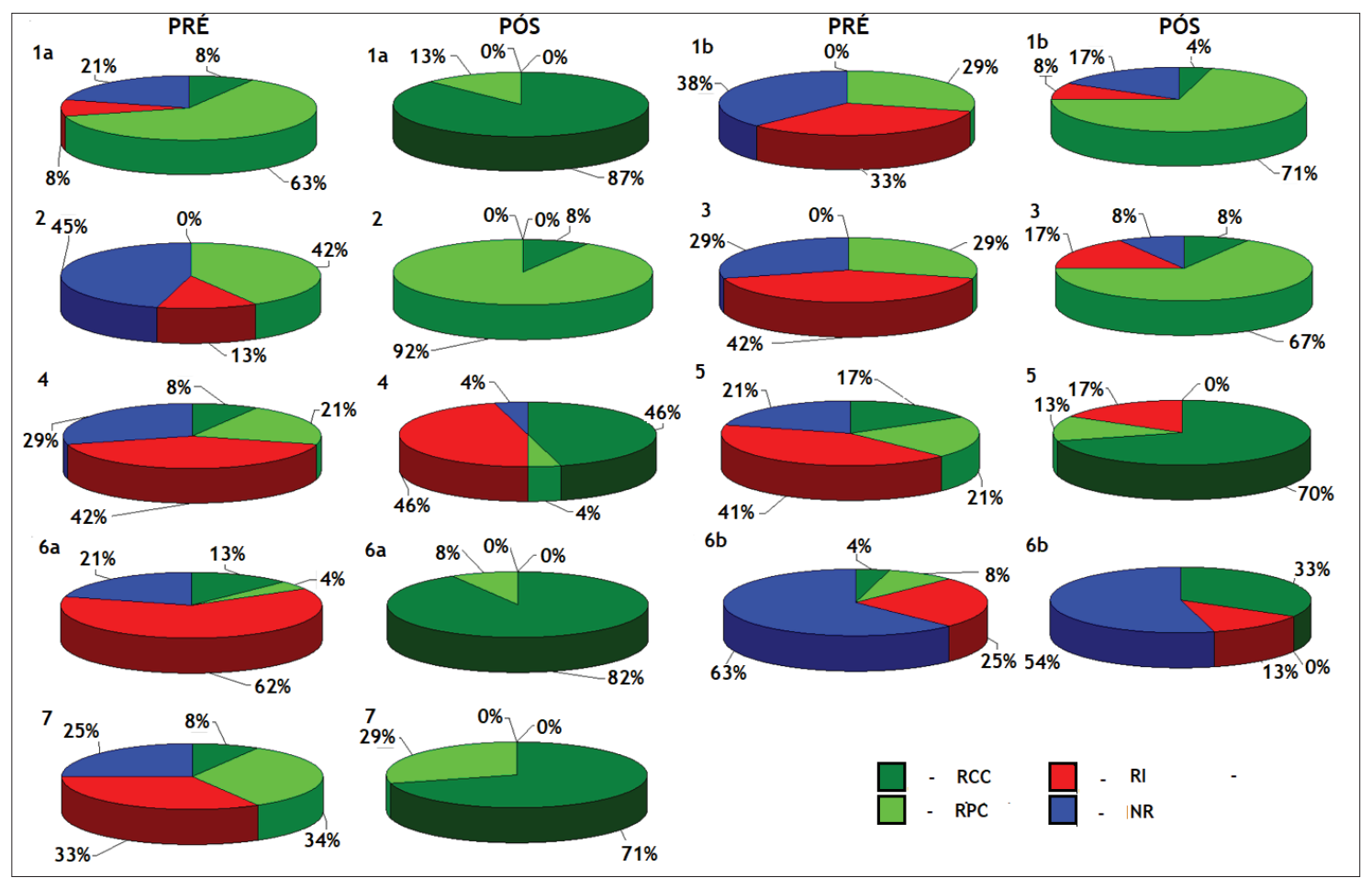

Fig. 1 - Resultados obtidos no PRÉ e PÓS questionário.

RCC - Respostas Cientificamente Corretas; RPC - Respostas Parcialmente Corretas; RI - Respostas Incorretas; NR - Não Respondei.

Fig. 1 - RResults obtained in the PRE and POST test questionnaire.

RCC - Scientifically Correct Responses; RPC - Partially Correct Responses; RI - Incorrect Responses; NR - Not Responding. 
No que diz respeito à alínea b da $1 .^{a}$ Questão, no préquestionário nenhum aluno respondeu cientificamente correto (RCC) e apenas cerca de $29 \%$ responderam parcialmente correto (RPC). Do total dos alunos, à volta de $38 \%$ não respondeu (NR) e cerca de 33\% registou resposta incorreta (RI). Já no pós-questionário, os resultados obtidos indicaram que cerca de $4 \%$ dos alunos respondeu cientificamente correto (RCC) e aproximadamente $71 \%$ dos alunos respondeu parcialmente correto (RPC). Quando se consideram as respostas RCC e RPC os resultados mostraram que o valor inicial de $29 \%$ passou para $75 \%$, o que indicia que a estratégia usada, de lecionação, construiu conhecimento nos alunos.

Os resultados obtidos na 2. ${ }^{\text {a }}$ Questão mostraram que, no préquestionário, nenhum aluno respondeu cien-tificamente correto (RCC) e apenas $42 \%$ dos alunos responderam parcialmente correto (RPC). O número de alunos que não responde (NR) registou o valor de cerca de $45 \%$ e o número de alunos que responde incorretamente foi de aproximadamente $13 \%$. No pós-questionário, as respostas cientificamente corretas (RCC) e parcialmente corretas (RPC) foram $100 \%$, ou seja, cerca de $8 \%$ RCC e de $92 \%$ RPC. É um resultado muito interessante, pois a estratégia anulou $58 \%$ de respostas incorretas e não respondidas.

Por sua vez, os resultados da $3 .^{\text {a }}$ Questão mostraram que, inicialmente, $71 \%$ dos alunos ou responderam incorretamente $(42 \%$ RI) ou não responderam $(29 \%$ NR) e apenas cerca de $29 \%$ dos alunos responderam parcialmente correto (RPC). No pós-questionário os resultados obtidos mostraram que a estratégia usada melhorou substancialmente o conhecimento científico dos alunos, registando 75\% de RCC e RPC.

$\mathrm{Na} 4 .^{\text {a }}$ Questão, no pré-questionário os resultados obtidos mostraram que $71 \%$ dos alunos ou não responderam (NR $29 \%$ ) ou responderam incorretamente (RI $42 \%$ ) e que cerca de $8 \%$ dos alunos responderam cientificamente correto (RCC) e $21 \%$ responderam parcialmente correto (RPC). Em contrapartida, no pós-questionário os resultados indiciam uma melhoria substancial, no entanto é de salientar que o número de respostas incorretas (RI) perfez um total de $46 \%$. O número de alunos que não responderam (NR) passou de $29 \%$ para cerca de $4 \%$, o que revela que houve uma mudança de resposta, no entanto os resultados sugerem que não houve construção suficiente de conhecimento. É digno de nota que as RCC passaram de $8 \%$ para cerca de $46 \%$ e as RPC registaram o valor de $4 \%$. Se adicionarmos as respostas RCC e RPC o resultado obtido é de cerca de $50 \%$.

Em relação à $5 .^{\text {a }}$ Questão, os resultados do préquestionário mostraram que cerca de $17 \%$ dos alunos responderam RCC, $21 \%$ dos alunos RPC, $41 \%$ dos alunos RI e $21 \%$ dos alunos NR. Já no pós-questionário os resultados mostraram que os alunos construíram conhecimento. Todos os alunos responderam e apenas cerca de $17 \%$ dos alunos registaram RI. Das respostas corretas, cerca de $70 \%$ foram RCC e $13 \%$ responderam RPC.

$\mathrm{Na}$ Questão 6.a, os resultados comparativos entre pré e pós-questionário sugerem que os alunos construíram conhecimento científico, uma vez que no pré-questionário apenas cerca de $17 \%$ dos alunos responderam $13 \%$ de RCC e 4\% RPC e após a aplicação do pós-questionário o resultado passou para $100 \%$, ou seja, RCC $92 \%$ e RPC $8 \%$. Se no pré-questionário se registaram cerca de $62 \%$ de RI e de $21 \%$ dos alunos NR, a abordagem da temática anulou, na sua totalidade, o resultado de $83 \%$ (RI + NR) para um resultado de $0 \%$ no pós-questionário. Pode considerarse que a abordagem de imagens e a sua interpretação parecem construir conhecimento científico nos alunos.

Na Questão 6.b, 63\% de alunos não responderam (NR) e $25 \%$ responderam incorretamente (RI). Dos $12 \%$ que responderam corretamente, $4 \%$ foram RCC e $8 \%$ RPC. Nesta questão os alunos deveriam ter respondido que os animais identificados na alínea anterior são prejudiciais para a horta. Esta questão mostrou ser a que deverá merecer mais atenção numa próxima abordagem da temática, uma vez que os alunos, na sua maioria, não construíram conhecimento. Os resultados obtidos no pré-questionário mostraram que $88 \%$ das respostas incluem $63 \%$ de NR e $25 \%$ de RI. O valor de $88 \%$ foi reduzido para $67 \%$ no pósquestionário, que passou a incluir cerca de $13 \%$ de RI e $54 \%$ de NR. Também, os resultados obtidos no pós-questionário mostraram que as RCC registaram $33 \%$ e as RPC $0 \%$ e não se registou nenhuma RPC.

Por último, na 7. ${ }^{\mathrm{a}}$ Questão, os alunos deveriam unir os pontos entre duas imagens. No pré-questionário, cerca de $8 \%$ dos alunos responderam cientificamente correto (RCC), enquanto $34 \%$ de alunos responderam parcialmente correto (RPC), à volta de $33 \%$ dos alunos responderam incorretamente (RI) e aproximadamente $25 \%$ dos alunos não responderam (NR). Após a abordagem da temática os resultados obtidos foram muito positivos, dado que no pós-questionário cerca de $71 \%$ dos responderam cientificamente correto (RCC) e $29 \%$ dos alunos responderam parcialmente correto (RPC). Não se registaram respostas incorretas (RI) nem ausência de resposta (NR). Os alunos, na sua grande maioria, ou seja, mais de 70\%, construíram conhecimento científico e completo, pois uniram os pontos de forma correta.

Quando se consideram as respostas de RCC+RPC, a comparação dos resultados obtidos no PRÉ ePÓS questionário é muito clara (fig. 2). A vantagem de se apresentarem num gráfico de colunas está na perceção visual dos resultados que podem ser quantificados na ordenada. 0 gráfico permite conhecer a posição dos resultados (RCC + RPC) em $\%$, para cada questão. São indicadas três linhas horizontais, uma de $25 \%$; outra de $50 \%$ e, uma terceira, de $75 \%$. A linha de $50 \%$ permite, através da observação visual, reconhecer que são as questões 4 e 6.b que merecem preocupação, numa nova aplicação da estratégia. 


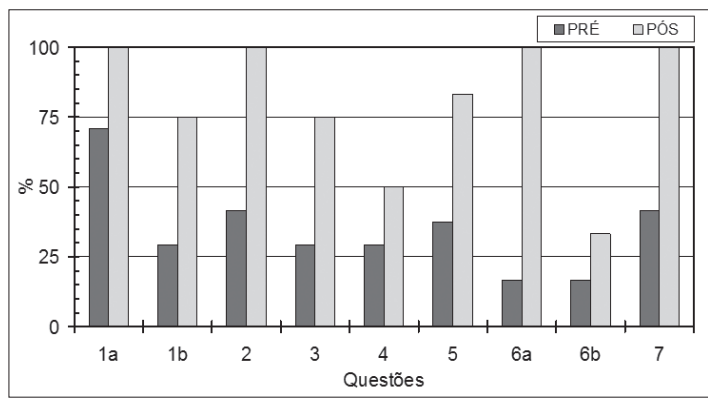

Fig. 2 - Resultados obtidos por coluna de (RCC+RPC) no PRÈ e Pós questionário.

Fig. 2 - Results obtained by $(R C C+P R C)$ column in the PRE and POST test questionnaire.

Para as questões 1.a, 2, 6.a e 7 os resultados obtidos no PÓS registaram $100 \%$ o que indicia que a estratégia adotada construiu conhecimento científico em todos os alunos.

A questão 1.b mostra que o resultado obtido no Pós foi de $75 \%$, muito acima da linha mínima de aprendizagem (de $50 \%$ ), o que corresponde a um aumento de cerca de $150 \%$ do PÓS face ao PRÉ. A questão 3 apresenta a mesma interpretação.

Os resultados obtidos para a questão 4 revelam alguma preocupação pois no Pós questionário apenas cerca de $50 \%$ dos alunos mostraram que construíram conhecimento. No entanto é bom salientar que do PRÉ para o PÓS se registou um aumento de aproximadamente $67 \%$. É uma questão que numa próxima aplicação da estratégia deverá ser reestruturada.

A questão 5 registou, no PÓS, um valor de cerca de 119\% o que significa que houve um aumento de cerca de $115 \%$ face aos valores registados no PRÉ.

A questão 6.b revela grande preocupação pois, mesmo depois de aplicada a estratégia, os resultados obtidos no PÓs foram inferiores a 50\% (cerca de 33\%). No entanto, é bom salientar que se registou um aumento no PÓS de cerca de $175 \%$ face ao PRÉ. Esta questão merece uma atenção cuidada em novas abordagens da temática.

\section{Aplicação numa extensão à sala de aula - horta}

Foi feita uma horta em terreno da escola para os alunos acompanharem a preparação do solo, a plantação de diferentes plantas e observarem o seu desenvolvimento em céu aberto e em estufa. 0 solo era do tipo argiloso e estava muito seco, com presença de algumas ervas daninhas. Na fronteira da horta foi construída uma vedação, constituída por garrafas de água, de material plástico, de 1,5L de capacidade.

Vários garrafões de $5 \mathrm{~L}$ foram cortados na base e preparados para funcionarem como estufas e, também, como proteção contra a invasão de animais. Para segurar os garrafões na vertical, foram preparadas estacas, feitas de varas finas. Para prender os garrafões às estacas usouse arame fino, que se aplicou no gargalho dos garrafões.

Os alunos foram divididos em grupos e as plantas foram previamente identificadas com os números correspondentes a cada grupo. Para controlo, foram selecionadas duas plantas de cada espécie, nomeadamente couves e alfaces (em céu aberto e cobertas por garrafões) e, também, cenouras e pimenteiros em céu aberto. Depois, todas as semanas e durante cerca de 8 semanas, foram realizadas observações e registou-se o estado do tempo, a temperatura do ar (em céu aberto ou em estufa) e a medida do desenvolvimento, bem como se procedeu à monda e à rega das plantas.

Os alunos reconheceram que a temperatura do ar era mais alta no interior dos garrafões, comparativamente com o registo em céu aberto, e reconheceram que a parede interna dos garrafões apresentava gotas de água e algumas a escorrerem para o solo, originando uma rega natural e noturna.

A análise comparativa do desenvolvimento de alfaces em céu aberto e em estufa mostrou diferenças (fig. 3). Assim, em qualquer das imagens, a alface na estufa está mais desenvolvida do que a exposta ao céu aberto, o que mostrou a vantagem de crescer numa temperatura mais uniforme, estar protegida de animais e registar uma rega natural por condensação do vapor de água na parede interna dos garrafões.

A observação da imagem central da fig. 3 mostra, inequivocamente, como a rega natural se realiza com água retirada da atmosfera, pelo arrefecimento do ar durante a noite, a qual se formava na parede interior dos garrafões por condensação do vapor de água. Os alunos puderam observar e acompanhar o processo de rega natural e construíram conhecimento. Pelo seu conhecimento informal mostraram ter uma excelente participação na troca de ideias e na construção de conhecimento científico. Alguns alunos mostraram tanto interesse que reconheceram a razão de muitas pessoas usarem garrafões nas hortas em aldeias e compreenderam como é possível fazer uma rega natural se a atmosfera junto à horta tiver um arrefecimento que permita o aparecimento de água na parede interna dos garrafões (M. Talaia e C. Vigário, 2016). Para os alunos compreenderem bem o que se passava durante a noite, foi retirado um garrafão e ficaram surpreendidos. Houve expressões como "que giro ... está mesmo regado".

A fase de registo de dados foi outro aspeto importante do desenvolvimento do projeto (fig. 4). A imagem do lado esquerdo, mostra plantas em estufa que eram medidas, após a retirada dos garrafões, usando uma fita métrica. Por sua vez, os garrafões mostram água na sua parede interna. A imagem central mostra a medição da altura de uma couve em céu aberto. 
A imagem do lado direito mostra a colocação do termómetro no interior do garrafão durante cerca de um minuto, para medir a temperatura do ar no seu interior. A temperatura do ar em céu aberto era a última variável a ser registada.

Com base nos registos assim obtidos, construíram-se gráficos para mais facilmente os alunos acompanharem o desenvolvimento das quatro plantas estudadas: couve, alface, cenoura e pimenteiro (fig. 5). Foram usados dados para um período de cerca de 55 dias depois das plantas serem colocadas no solo, ou seja, cerca de 8 semanas.

A observação mostrou que, para a couve e alface, as alturas registadas são comparáveis em termos do desenvolvimento em céu aberto e em estufa. No entanto, os resultados mostraram um maior desenvolvimento das plantas no interior de uma estufa.

Por outro lado, a observação visual permitiu ainda verificar que, independentemente da planta, seja em céu aberto ou em estufa, o desenvolvimento mais acentuado ocorreu nos primeiros 15 dias após as plantas serem colocadas no solo (fig. 5). Este facto permitiu discutir com os alunos algumas ideias acerca desta situação. No geral, todos concordaram que o solo era pobre, muito duro para o desenvolvimento de plantas, do tipo argiloso e pobre em nutrientes. Os alunos construíram conhecimento ao reconhecerem que o tipo de solo para o desenvolvimento das plantas condiciona o seu desenvolvimento. Os alunos também reconheceram que as plantas em céu aberto tiveram ataque de animais.

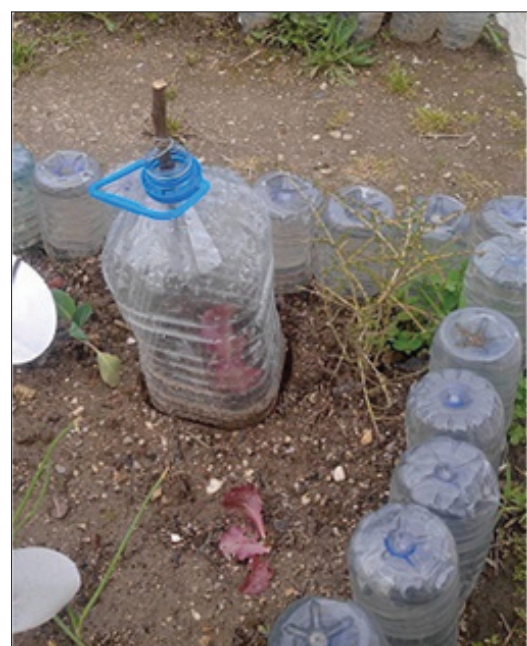

Alface: céu aberto e estufa, fase 1

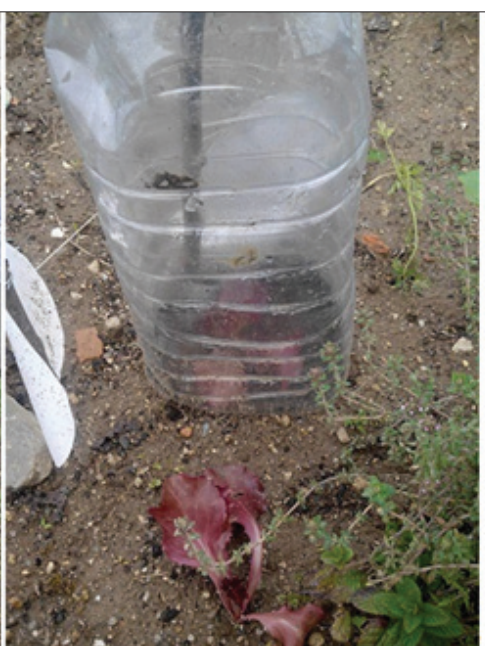

Alface: céu aberto e estufa, fase 2

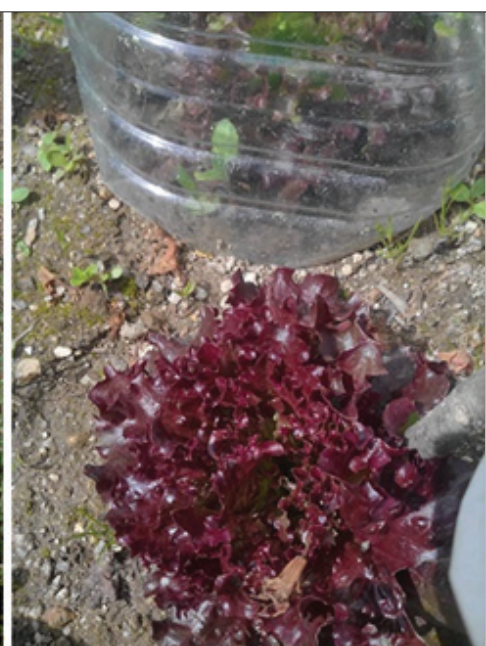

Alface: céu aberto e estufa, fase 3

Fig. 3 - A horta: diferentes momentos do desenvolvimento de alfaces.

Fig. 3 - The vegetable garden: stages in the development of lettuces.

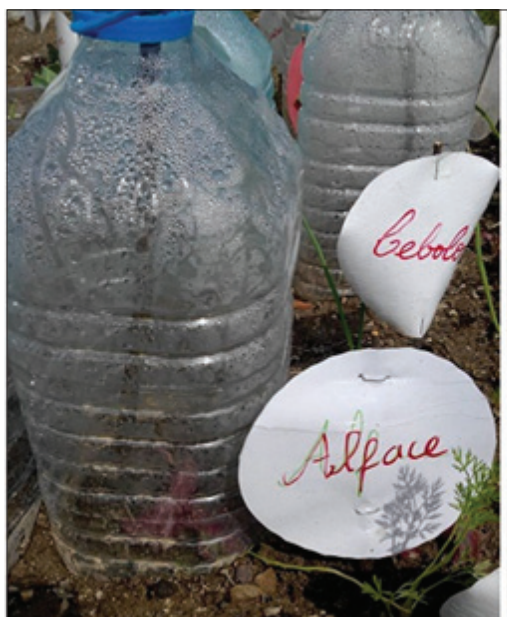

Água na parede interna do garrafão

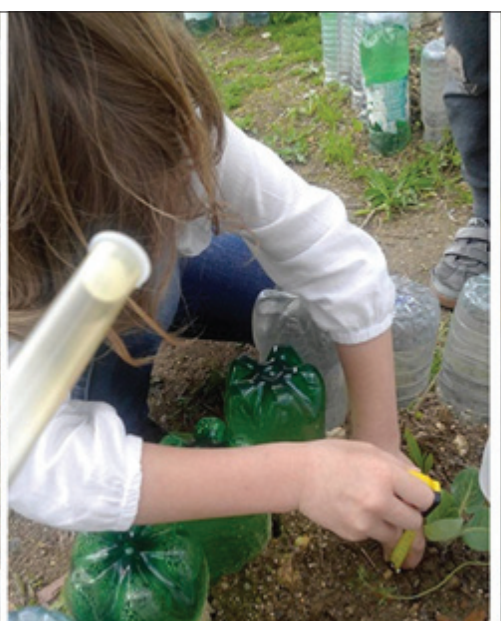

Altura da couve

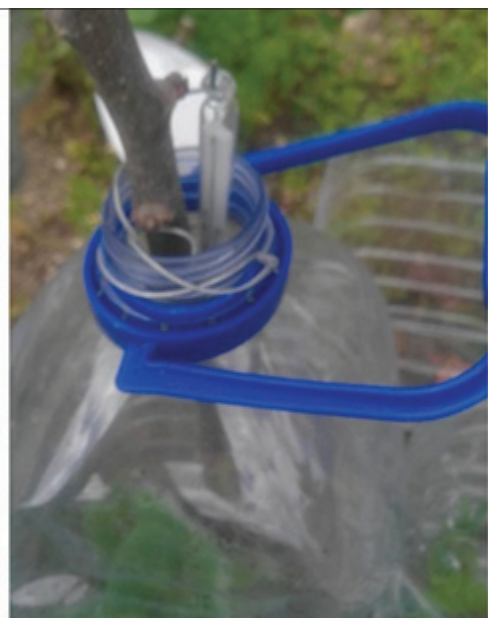

Temperatura interior do ar

Fig. 4 - Medições da altura de plantas e avaliação da temperatura do ar.

Fig. 4 - Measurement plant height and air temperature. 


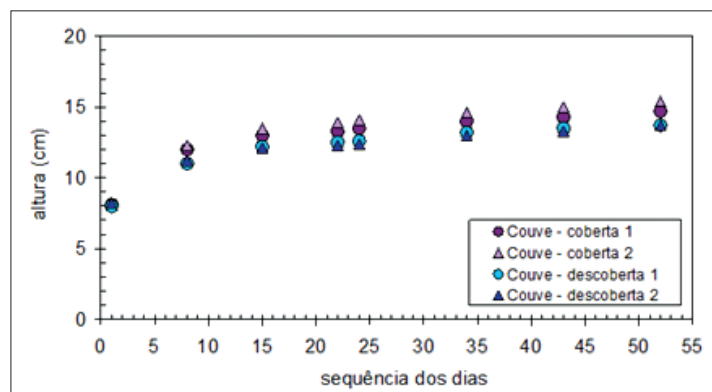

Desenvolvimento $\cdot d a \cdot c o u v e \cdot a \cdot c e ́ u \cdot a b e r t o \cdot e \cdot e m \cdot e s t u f a$

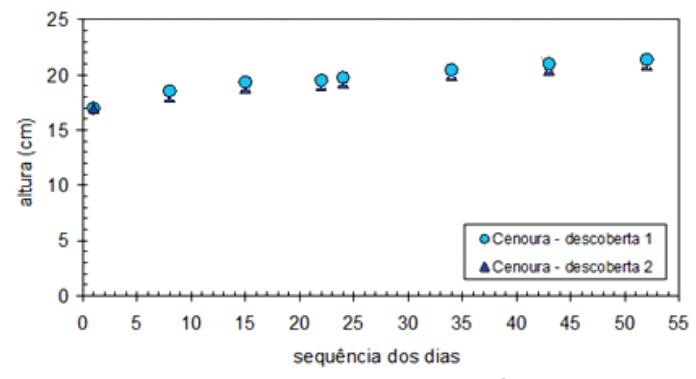

Desenvolvimento·da·cenoura·a·céu·aberto

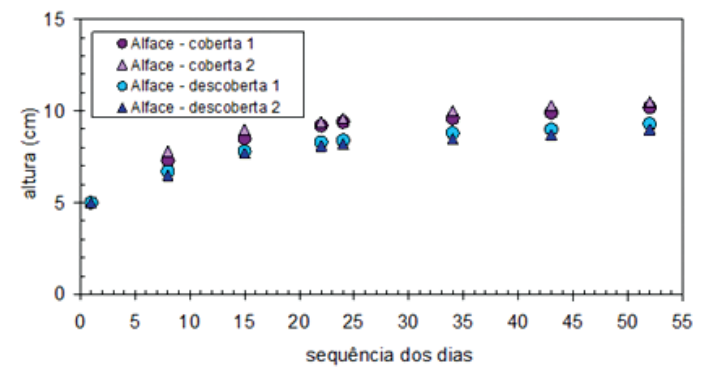

Desenvolvimento·da·alface $\cdot a \cdot c e ́ u \cdot a b e r t o \cdot e \cdot e m \cdot e s t u f a$

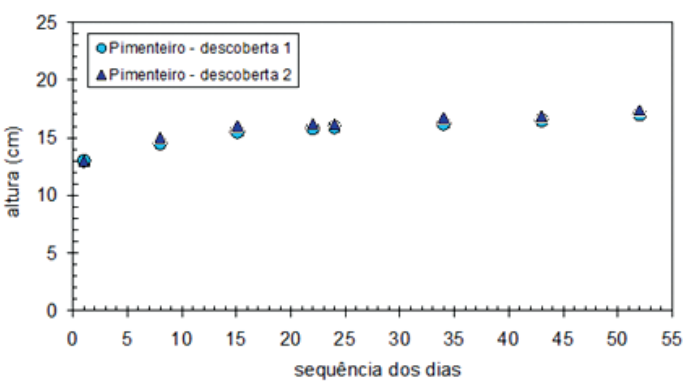

Desenvolvimento·do·pimenteiro·a·céu·aberto

Fig. 5 - Resultados obtidos para as plantas em céu aberto e em estufa.

Fig. 5 - Results obtained for open air and greenhouse plants.

\section{Conclusões}

É sabido que o ser humano tem procurado, ao longo dos tempos, conhecer como as plantas se desenvolvem e que tipo de ambiente é o mais aconselhável para esse desenvolvimento. Sensibilizar os alunos para esta problemática foi uma tarefa gratificante, pois os alunos, como futuros cidadãos, mostraram interesse na procura de conhecimento.

$\mathrm{Na}$ abordagem da estratégia por aplicação do questinário destacam-se as questões 4 e $6 \mathrm{~b}$ que registaram resultados menos animadores. Numa próxima aplicação da estratégia devem ser reestruturadas.

Neste trabalho, através da criação de uma horta, os alunos compreenderem como as plantas se desenvolvem em diferentes espaços (em céu aberto e em estufa), e reconheceram que há animais que podem ajudar ou prejudicar o desenvolvimento de plantas.

Durante a aplicação da estratégia, os alunos identificaram alguns fatores do ambiente que condicionam a vida das plantas como, por exemplo, a luz, a água e o tempo atmosférico. Reconheceram que uma horta é um local de aprendizagem e conhecimento sobre o desenvolvimento de plantas e que aqueles que visitam familiares a residir em zonas rurais mostraram já ter um excelente conhecimento através de uma aprendizagem informal.

Este trabalho mostra que a Educação Científica assume um papel fundamental na compreensão das problemáticas que a humanidade enfrenta, na consciencialização da responsabilidade do ser humano na situação planetária atual, devendo promover o desenvolvimento de cidadanias proativas, fundamentadas e responsáveis, no sentido da mudança, numa perspetiva crítica global que garanta a sustentabilidade do planeta. Se os educadores implementarem, nas práticas letivas, atividades em extensão da sala de aula como, por exemplo, a criação de uma horta, podem reforçar o interesse dos alunos e despertar a vontade de eles próprios cultivarem a terra quando crescerem, fixando-se em zonas rurais, evitando assim deixar os terrenos agrícolas abandonados ou entregues às plantações de eucaliptos e/ou pinheiros, que são facilmente inflamáveis e de grande combustibilidade.

Os resultados deste trabalho não devem ser generalizados devido ao tamanho da amostra, no entanto, contribuem de forma valiosa para a formação de futuros cidadãos e pelo respeito pela sustentabilidade do planeta e proteção da floresta.

Por último, pode-se afirmar que as zonas rurais onde ainda são criadas hortas facilitam uma melhor cidadania e um melhor respeito pela natureza.

\section{Referências bibliográficas}

Cohen, L., Manion, L. e Morrison, K. (2010). Research Methods in Education (6. ${ }^{\mathrm{a}}$ ed.). New York: Routledge.

COMISSÃO EUROPEIA (2013). Comunicação da Comissão ao Parlamento Europeu, ao Conselho, ao Comité Económico e Social Europeu e ao Comité das Regiões - 
Uma vida digna para todos: Erradicar a pobreza e dar ao mundo um futuro sustentável. COM (2013) 92 final.

Driver, R., Newton, P. e Osborne, J. (2000). Establishing the norms of scientific argumentation in classrooms. Science Education, 84(3), p. 287-312

EUROPEAN MULTI-STAKEHOLDER STEERING GROUP ON DEVELOPMENT EDUCATION (2007). O Consenso Europeu sobre o Desenvolvimento: $O$ contributo da educação para o desenvolvimento e da sensibilização.

IPCC (2014a). Climate Change 2014: Mitigation of Climate Change. Intergovernmental Panel on Climate Change Contribution of Working Groups III.

IPCC (2014b). Climate Change 2014: Synthesis Report. Intergovernmental Panel on Climate Change Contribution of Working Groups I, II and III.

Gomes, C., Brocardo, J., Pedroso, J., Carrillo, J., Ucha, L., Encarnação, M., Horta, M., Calçada, M., Nery, R. e Rodrigues, S. (2017). Perfil dos Alunos para o século XXI. Coord Martins, G. O., Editor Ministério da Educação, República Portuguesa - Educação, 24 p.

Martins, I. (2002). Problemas e perspetivas sobre a integração CTS no sistema educativo português. Revista Eletrónica de Enseñanza de las Ciências, 1(1).

MINISTÉRIO DA EDUCAÇão (2004). Organização Curricular e programas $10^{\circ}$ Ciclo do Ensino Básico - Estudo do Meio. (4. ${ }^{\mathrm{a}}$ ed.). Editor: Departamento da Educação Básica. Ministério da Educação.

Morin, E. (1999). Os Sete Saberes Para a Educação do Futuro. Instituto Piaget Horizontes Pedagógicos.

NATIONAL-RESEARCH-COUNCIL (2014). Literacy for Science: Exploring the Intersection of the Next Generation Science Standars and Common Core for ELA Standards, A Workshop summary, H. Rhodes and M. A. Feder, Rapporteurs. Steering Committee on Exploring the Overlap between "Literacy in Sci". Wasshigton DC: The National Academies Press.
OECD (2015). Final NAEC Synthesis. New Approaches to Economic Challenges. Meeting of the Council at Ministerial Level. Paris, 3-4 de Junho de 2015.

Talaia, M. e Vigário, C. (2016). Temperatura de ponto de orvalho: um risco ou uma necessidade. Geografia, Cultura e Riscos. Livro de Homenagem ao Prof. Doutor António Pedrosa. Luciano Lourenço (Coords.), Imprensa da Universidade de Coimbra, p. 169-197. DOI: https://doi.org/10.14195/978-989-26-1237-9_7

Torres, A., Figueiredo, I., Cardoso, J., Pereira, L., Neves, M. e Silva, R. (2016). Referencial de Educação para o Desenvolvimento - Educação Pré-Escolar, Ensino Básico e Ensino Secundário. Coordenadores Cardoso, J., Pereira, L., Cabral, A. E Neves, M., Editor Ministério da Educação, 79 p.

UNESCO (2005). Draft International implementation scheme for the United Nations Decade of Education for Sustainable Development. Paris: United Nations Educational, Scientific and Cultural Organization.

UNESCO (2014). Roadmap for Implementing the Global Action Programme on Education for Sustainable Development. United Nations Educational, Scientific and Cultural Organization, Paris, France

UNITED NATIONS (2013). A new global partnership: Eradicate poverty and transform economies through sustainable development. The Report of the HighLevel Panel of Eminent Persons on the Post-2015 Development Agenda. New York.

UNFPA - UNITED NATIONS POPULATION Fund (2007). State of world population 2007. Unleashing the Potential of Urban Grouth. New York: UNFPA.

Vilelas, J. (2009). Investigação: O processo de construção do conhecimento. Lisboa: Edições Sílabo. 